\title{
Do Local Residents Support the Development of a National Park? A Study from Nanling National Park Based on Social Impact Assessment (SIA)
}

\author{
Qian Dong ${ }^{1}$, Bo Zhang ${ }^{2,3, * \mathbb{D}}$, Xiaomei Cai ${ }^{2}$ and Alastair M. Morrison ${ }^{4}$ \\ 1 School of Tourism and Hospitality Management, Hubei University of Economics, Wuhan 430205, China; \\ qdong@hbue.edu.cn \\ 2 School of Tourism Management, South China Normal University, Guangzhou 510631, China; \\ caixm@scnu.edu.cn \\ 3 Southern Marine Science and Engineering Guangdong Laboratory, Zhuhai 519085, China \\ 4 Department of Marketing, Events and Tourism, Greenwich Business School, University of Greenwich, \\ London SE10 9SL, UK; a.morrison@greenwich.ac.uk \\ * Correspondence: zhangborug@m.scnu.edu.cn
}

Citation: Dong, Q.; Zhang, B.; Cai,

X.; Morrison, A.M. Do Local

Residents Support the Development of a National Park? A Study from Nanling National Park Based on Social Impact Assessment (SIA). Land 2021, 10, 1019. https://doi.org/ 10.3390/land10101019

Academic Editor: Hossein Azadi

Received: 28 August 2021

Accepted: 24 September 2021

Published: 28 September 2021

Publisher's Note: MDPI stays neutral with regard to jurisdictional claims in published maps and institutional affiliations.

Copyright: (c) 2021 by the authors. Licensee MDPI, Basel, Switzerland. This article is an open access article distributed under the terms and conditions of the Creative Commons Attribution (CC BY) license (https:// creativecommons.org/licenses/by/ $4.0 /)$.

\begin{abstract}
Over the past five years, the pilot establishment of national parks in China has been a major event in global biodiversity conservation. The national parks under construction and proposed account for nearly $1 \%$ of the land area, and their social impacts have attracted the attention of researchers and managers. However, most of the research has a focus on the effects of protection, and national parks do not have a sufficient understanding of the social impacts and perceptions of the local residents. This research, taking Nanling National Park in Guangdong Province as the case, used the social impact assessment research framework to explore the perceptions and support of local people for the creation of national parks. Through questionnaires and in-depth interviews, the findings were first that most residents expressed a low awareness of Nanling National Park's development, but they still expressed conditional support. Second, ethnic minorities and less educated residents did not support the creation of national parks. Perceptions of ecological, economic, political, and cultural impacts affected whether residents supported the construction of national parks. In the initial stages of national park development, governmental administrative departments should reduce the negative impacts of national park construction by strengthening the publicity and awareness building, formulating appropriate policy guidance for different needs, and giving local residents the right to express their views, so as to enhance resident support for national park projects.
\end{abstract}

Keywords: Nanling National Park; social impact assessment (SIA); protected areas; resident perceptions; livelihoods

\section{Introduction}

A "national park"(NP) according to the International Union for Conservation of Nature (IUCN), is a large natural or near-natural area set aside to protect large-scale biological processes, as well as species and ecosystem characteristics [1]. As a significant type of protected area (PA), NPs not only conserve biodiversity but also offer opportunities for spiritual uplifting, science, education, recreation, and tours that are compatible with the environment and culture of the area [2]. More importantly, they potentially contribute to the eradication of poverty and minimize excessive demands on nature, thereby promoting sustainable livelihoods for local communities [3,4]. NPs feature both natural and social attributes, making them an example of a socio-ecosystem. There is one authoritative policy document in China, the "Overall Plan on the Construction of National Park System", which was released in 2017 by the Central Government. It provides the official definition for China as "a national park is authorized by the Central Government and implemented by government-led management, set up on specific land, marine and ocean areas to conserve 
ecological systems of large size and national representativeness, and aimed at achieving a combination of ecological conservation and reasonable development". Except for national representativeness, national parks in China have two unique characteristics, which are different from those in the protected area classification system of the IUCN: ecological conservation as a first target and public benefits for all people. Consequently, China is devoting more administrative resources to conservation. In some cases, the real goal is environmental protection, which means all resource exploitation has been prohibited, and this creates a predicament for the local communities. As such, there should be a focus on improving the well-being of the local residents in the surrounding areas while preserving the biodiversity throughout national park (hereafter NP) development.

More NPs will be established in China during the 14th Five-Year Plan, covering 6-9\% of the country's land area, according to the spatial layout plan for NPs. Influenced by the global paradigm shift [5], the creation of PAs in China is beginning a transition from protection to conservation. China started building the first batch of pilot national parks in 2015. (At present, China has not officially established formal NPs, while a system of pilot NPs with 10 members has existed for six years and another batch of new NPs will be set up by the end of 2021. From a practical point of view, there is no substantial difference between these areas, and the ongoing construction work and the impacts on local communities are similar. Considering the research topic, these pilots are called NPs in general without distinction.) However, because less attention was paid to the social aspects during the initial stage of constructing NPs, the "one-size-fits-all" policy-i.e., forced eviction and relocation of residents in protected areas-was generally followed. A slew of adverse social consequences emerged and persisted-for example, the strict control of natural resources resulted in the physical and economic displacement of native groups and the local residents found it difficult to adapt to changes in cultural and social systems; conflicts arose from the adjustment of community livelihoods; and the redistribution of rights in the communities led to inequality with respect to public resource allocation [6].

"Man-land constraint" issues have become more visible with China's NPs, owing to the large numbers of residents and collectively owned land. Given the constraints imposed by the "strictest conservation" policy (in September 2017, "the General Plan for Establishing National Park System" was officially promulgated. In the plan, it is mentioned that the NP area will be included in the national ecological protection red line area control scope in China, and the "strictest conversation" will be implemented, all activities damaging the ecosystem will be prohibited), how can the goal of preserving and managing ecological systems in NPs be fulfilled while minimizing the negative social impacts on communities and garnering resident support? With the global knowledge and expertise in PA management, as well as the experiences gained from the first batch of pilot NPs, the National Forestry and Grassland Administration (NFGA) (the National Forestry and Grassland Administration (NFGA), which is also the National Park Administration(NPA), is in charge of the related affairs of NP at the central government level) is mandating the completion of social impact assessments (SIA) on the next batch of proposed NPs (There were ten pilot areas in the first batch of NPs under construction in China. The acceptance of the pilot areas has been completed in 2020 and is expected to be formally established in 2021. The construction of the second batch of national parks was initiated from 2016 to 2020, and Nanling National Park is one of them.) in advance of their construction. There are two primary reasons for this new requirement. First, the establishment of NPs can effectively protect ecological environments while simultaneously sustaining local socio-economic progress. An SIA is usually undertaken by the appropriate functional departments of NPs, municipal governments, and local communities. The direct participation of the local residents can reveal the potential social issues and contradictions that may arise in the construction process, allowing more targeted policies and guidelines to be developed. Second, the local residents and communities in and around a NP are the key subjects for socio-economic impact assessment. In a centralized country like China, however, these groups have less power to voice their opinions that might influence public sector policy while NPs are being built. 
Worse still, their positions of uncertainty with respect to NP construction is exacerbated by a lack of available information. On the one hand, a high reliance on natural resources for survival, including land, and a strong emotional attachment to their homelands, drive local residents to oppose the establishment of national parks in principle. On the other hand, they must make concessions to the implementation of national macroeconomic policies aimed at ecological reform and sustainability. The social consequences of NP development not only influence ecological conservation at a macro level, but also the livelihoods and everyday lives of local people through path dependency [7].

Guangdong Nanling National Park (NNP) is a NP explicitly proposed in the "National Park Spatial Layout Plan" and construction work started in 2018. NNP has typical manland constraints (there is much collective land in the proposed NPs, and there are serious land disputes. At the same time, there are large numbers of residents living in the Nanling region, and some of them are ethnic minorities. Both are typical issues in China's pilot NPs which cause social conflicts) and its communities are widely representative of China's NPs. Based on the SIA survey data from residents in the proposed lands for NNP and its surrounding area, this research addressed the following questions: What are the social impacts of national parks on communities? What factors affect resident perceptions of NPs? How do residents perceive the social impacts brought by the construction of NPs? Do the perceived social impacts by residents have an impact on their attitudes about supporting the construction of a NP?

\section{Literature Review}

As an evaluation index system, a social impact assessment (SIA) was first proposed by Mendoza in the 1970s. Vanclay defined social impact as "the processes of analyzing, monitoring and managing the intended and unintended social consequences, both positive and negative, of planned interventions, and of any social change processes invoked by those interventions. Its primary purpose is to bring about a more sustainable and equitable biophysical and human environment" [8,9].

A SIA is similar to an environmental impact assessment (EIA), but the difference is that a SIA emphasizes the impact on communities and pays more attention to the management not just the prediction of impacts. The social impacts can include various problems related to lifestyles, culture, and community (e.g., cohesion, political system, environment, health and well-being, personal and property rights, and fear and change of wishes) [10,11] Therefore, a SIA is not only a method that produces a report, but also represents a practical way to understand and manage the social impacts of projects.

Scholars are paying greater attention to the endogenous (internal) influences (local attachment, community empowerment, social capital, etc.) brought by exogenous (external) factors (policies, welfare policies, etc.) to communities. Top-down management systems have obvious effects on the formation of social influences [12]. The existing literature on the influences of the development of PAs on local areas can be categorized into ecological, economic, cultural, and political impacts [13]. Some of the most common and far-reaching social impacts brought by the development of PAs are seen in the changes in ecological environments and the spread of ecotourism. Strict ecological protection policies restore local natural environments, and by limiting certain human activities in specific areas, the rational use of ecological environments is more compatible with biodiversity conservation [14]. People living in and around nature reserves interact with ecotourism. Ecotourism brings tourists from other places, not only providing new sources of income for the local residents, but also creating natural, cultural, and social relationships in areas that did not previously exist. Ecotourism and nature-based tourism are newer ways to view and utilize the existing social-ecological landscapes surrounding people and create new boundaries $[15,16]$. However, some think that ecotourism has neither ecological nor social benefits $[17,18]$, but it nevertheless is still a strategy for protection and development. The establishment of PAs usually means that there is a significant positive impact on jobs by creating new employment 
opportunities [19]. Even if there is no ecotourism, the PA often provides employment opportunities for local residents [12].

Due to the development of tourism and recreational activities and changes in natural resource utilization, the development of PAs is affecting poverty levels [20]. The literature suggests that PA construction may have a significant negative effect on the incomes of local communities [21]; however, more recently, there is strong evidence that PAs reduce poverty levels [22-24]. A study in China's Qianjiangyuan (QJY) National Park showed that during its pilot period from 2015 to $2019,53 \%$ of respondents' annual net income remained unchanged, $37 \%$ of respondents' annual net income increased, and another $10 \%$ declined. Some $46 \%$ of the respondents had positive views on QJY, $11 \%$ held negative views, and $43 \%$ thought the park had no impact on their lives. QJY resident perceptions of economic changes affected their decision making in matters related to national parks. When they thought that the income from the national park development exceeded their previous income, they expressed support for the project [25].

To reduce the burden of PAs on local residents, the sharing of power and responsibilities between the government and local resource users is changing. PAs mean the application of new management frameworks, and this change often leads to the redistribution of power and the formation of alliances among different entities affected by the new authority [26]. The social impact of the unequal distribution of rights tends to have a greater impact on women and the poor. In the Maya Biosphere Reserve in Guatemala, planners regarded men as the "primary agents of social change", while they ignored women from the outset. Although the project was successful, it reasserted the local power structure and gender relationships. Because women were neglected, they began to form alliances and work outside their immediate families, which had a direct impact on the effectiveness of ecological protection in the reserve. Disadvantaged groups, especially ethnic minorities and poor people, have high expectations with respect to the establishment of PAs. They hope that in this process they can change identities and social standing, gaining a new social status and recognition. These hopes are reflected in their attitudes toward the PAs.

Conservation work changes people's perceptions of their relationship with the surrounding environment. Their daily lives are a reflection of the local culture. The interaction between work and life changes the local culture. For example, one of the outcomes of the Yellowstone National Park model is that it erased the cultural history of the Native Americans and the Native Americans themselves [27]. In the past, the Huaorani Indians believed that the natural environment was inseparable from their social world [28]. During the construction of the NP, they gradually realized that nature and culture were diverging. Research found that international non-governmental organizations imposed Western concepts on the separation of nature and culture on Thailand's PAs, which not only affected local cultures, but also led to strong resistance from local residents [29]. New languages and cultures penetrate into the local people's discourse and change and damage social life and customs. The effectiveness of the administrative system will depend on whether the affected community is willing to comply with new regulations implemented by the PAs and their social impacts. Social influences come into being with rumors about the establishment of PAs [30] and change with the development of projects [31]. Social impact is usually included in a broader category of well-being. The establishment of PAs not only changes local systems and social environments, including modes of land and water body ownership, but also affects the income inequality of rural people, depriving the residents of their rights to land and resources accompanied by unequal agricultural subsidies. These influences are often inherent and implicit but have a great impact on PA success. Compared with "technical and technocratic concerns" [32], the worries over non-technical issues, such as social impacts, are more limited and often cannot be effectively solved by managers [33].

Scholars generally measure the social impacts of PAs from three perspectives: the impacts of the PA on the whole population, the perceptions of managers and actors, and the perceptions of local communities. One of the goals of NPs is to improve the well-being of communities; therefore, a participatory process to gather the perceptions of the affected 
residents is considered critical in SIAs [34]. However, due to individual differences, people have dissimilar views, expectations, and concerns about projects. For example, excessive expectations can cause adverse social impacts, and when a project fails to meet expectations, residents feel "ripped off". To avoid such situations, when a new PA project starts, the focus should be on community expectations and the history that influences community perceptions, so as to gauge likely community support for the project. Vanclay [30] also believes that the influence of perceptions is a real influence, affecting people's behavior and attitudes. Although some studies provide guidance for improving the management of China's NPs, there is a lack of empirical research on the socio-economic impacts of NPs on local communities [35]. Based on the above review and analysis of the SIA framework, this research examined resident perceptions of the social impact caused by the NP from four perspectives: ecological, political, cultural, and economic impact perceptions.

\section{Research Setting}

\subsection{Study Site}

Nanling, straddling five provinces and regions (Guangdong, Jiangxi, Hunan, Fujian, and Guangxi), is the largest mountain range and a major natural geographical boundary in southern China. It is one of the 14 biodiversity hotspots in China and is recognized as a "treasure of species in subtropical regions" [36]. There is an abundance of natural vegetation (more than $70 \%$ cover), with 15 species classified as state key protected wildlife and plants. The proposed Nanling National Park (NNP), a typical Danxia landform in China's subtropical humid zone, is distinguished by its diverse formations and unique landscapes (Figure 1). In addition, Nanling is also a place of ancient cultural convergence, where the Central Plains and Baiyue civilizations interacted through the exchange of traditions, ideals, and languages. The north of Guangdong, where the NNP is to be established, is home to a variety of ethnic groups, the majority of whom are Hakka, a Han Chinese subgroup, as well as the Yao and She ethnic minorities. The proposed NNP is one of the second batch of pilot NPs identified by the NFGA, which comprises 14 protected natural areas—nine nature reserves, three forest parks, one geological park, and one wetland park. A number of essential preliminary works, such as adjusting and determining the scope and boundary of the NP, preparing the "Master Plan of NNP", and arranging PA administration agencies, are now being actively carried out. An application for the proposed NNP has been submitted to the NFGA. All of these initiatives will have a social influence at many levels in and around the park communities, namely in Qingyuan, Shaoguan, 7 counties (cities, districts), and 23 townships under the jurisdiction, which are the study sites in this research.

\subsection{Survey Design and Field Survey}

\subsubsection{Survey Design}

This research used a questionnaire survey as the main method to evaluate the perceived social impacts of the NNP project among residents within the local communities. The questionnaires examined the demographic characteristics of respondents and the expected social impacts of NNP development perceived by the residents in four impact categories-ecological, economic, political, and cultural. Since the construction of NNP is in the preparatory stage of initial construction, the perceived social impacts cannot be connected with specific construction initiatives. Therefore, to make the local residents better understand, the researchers developed easy-to-understand questions to ask whether the local residents perceived social impacts brought by the construction of NNP. Measurement items and phrases from previous research were adjusted to the Chinese context, as indicated in Table 1, to ensure the meaning and intent of each question could be clearly and correctly comprehended by the local residents. 


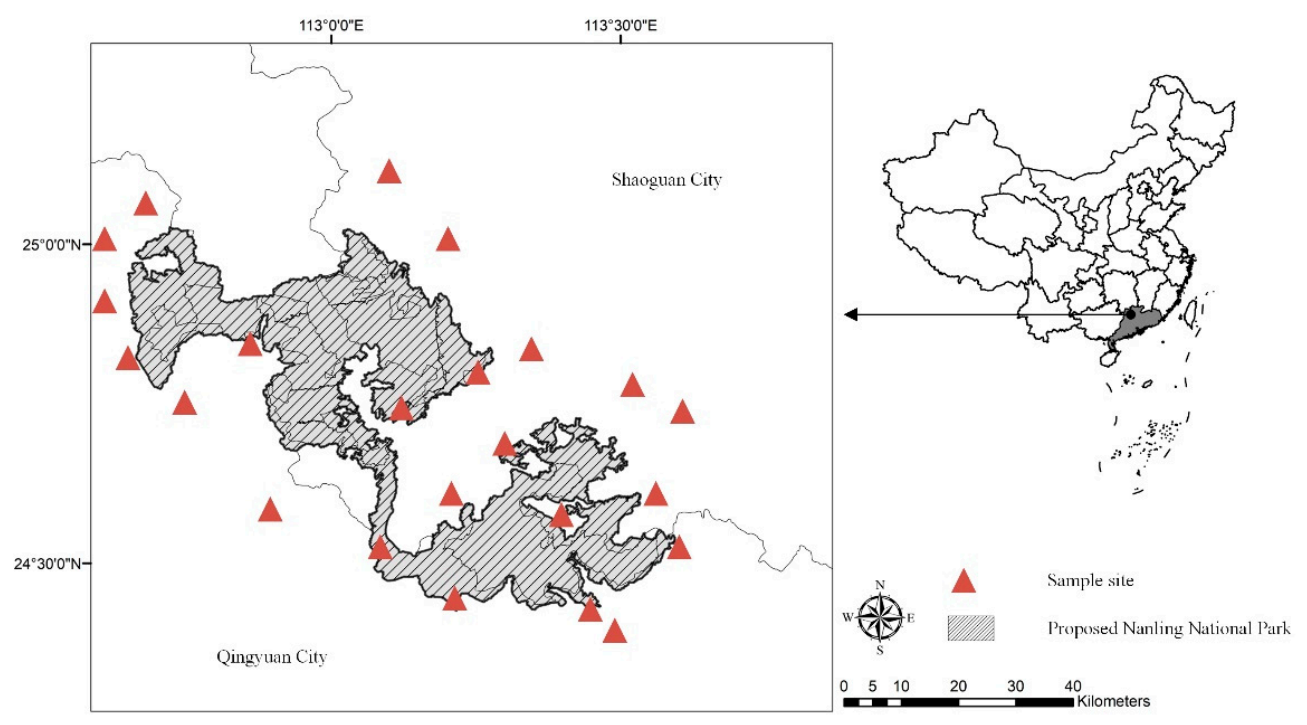

Figure 1. Proposed Nanling National Park study area (the area for the proposed Nanling National Park is still under discussion, and the map is only the initial proposed scope).

Table 1. Description of measurement indicators.

\begin{tabular}{|c|c|c|c|}
\hline Factors & Indicators & $\%$ & SE \\
\hline Do you support the construction of NPP? & $\begin{array}{c}1=\text { Yes } \\
2=\text { Yes (under certain } \\
\text { conditions) } \\
3=\mathrm{No}\end{array}$ & 57.9 & 0.625 \\
\hline \multicolumn{4}{|l|}{ Ecological impact perception (EL) } \\
\hline $\begin{array}{l}\text { Do you think NPP can improve the local } \\
\text { natural ecological environment? (EL 1) }\end{array}$ & $\begin{aligned} 1 & =\text { Yes } \\
2 & =\text { No } \\
3= & \text { Not clear }\end{aligned}$ & $\begin{array}{c}84.6 \\
2.0 \\
13.3\end{array}$ & 0.687 \\
\hline Economics impact perception (EC) & & & \\
\hline $\begin{array}{l}\text { Do you think NPP can promote the local } \\
\text { economic development as a whole? (EC 1) }\end{array}$ & $\begin{aligned} 1 & =\text { Yes } \\
2 & =\text { No } \\
3= & \text { Not clear }\end{aligned}$ & $\begin{array}{c}35.1 \\
4.5 \\
60.4\end{array}$ & 0.944 \\
\hline $\begin{array}{l}\text { Do you think NPP can promote the } \\
\text { development of local tourism? (EC 2) }\end{array}$ & $\begin{array}{c}1=\text { Yes } \\
2=\text { No } \\
3=\text { Not clear }\end{array}$ & $\begin{array}{c}82.2 \\
3.1 \\
14.7\end{array}$ & 0.717 \\
\hline Do you think NPP will increase the & $1=$ Yes & 79.8 & \\
\hline $\begin{array}{c}\text { employment opportunities of local community } \\
\text { residents? (EC 3) }\end{array}$ & $\begin{array}{c}2=\text { No } \\
3=\text { Not clear }\end{array}$ & $\begin{array}{c}4.4 \\
15.8\end{array}$ & 0.740 \\
\hline Political impact perception (PL) & & & \\
\hline Do you think NPP can benefit the poor? (PL 1) & $\begin{array}{c}1=\text { Yes } \\
2=\text { No } \\
3=\text { Not clear } \\
1=\text { Yes }\end{array}$ & $\begin{array}{c}28.6 \\
5.1 \\
66.3 \\
22.6\end{array}$ & 0.898 \\
\hline Do you think NPP can benefit women? (PL 2) & $\begin{array}{c}2=\text { No } \\
3=\text { Not clear }\end{array}$ & $\begin{array}{c}8.2 \\
69.1\end{array}$ & 0.838 \\
\hline $\begin{array}{c}\text { Cultural impaction perception (CL) } \\
\text { Do you think NPP has an impact on the } \\
\text { customs and religions of local ethnic minorities? } \\
\text { (CL 1) }\end{array}$ & $\begin{aligned} 1 & =\text { Yes } \\
2 & =\text { No } \\
3 & =\text { Not clear }\end{aligned}$ & $\begin{array}{l}19.4 \\
12.0 \\
68.5\end{array}$ & 0.799 \\
\hline
\end{tabular}

To ensure that the residents in each village and town were engaged and that the households were used as a sampling unit, a stratification method was employed for greater effectiveness based on the proportion of people living in each township. When the research team arrived at a research village, the existing resident were gathered in the conference rooms of the village committees, and the questionnaires were uniformly explained and completed to ensure consistency. From the residents who completed questionnaires, some 
were also interviewed according to their willingness to participate to better understand the reasons why they did not support the NNP project and the specific conditions for support. The interview questions were: "Have you experienced any difficulties during the development of NNP? What were these difficulties? ", "Why do you not support the development of NNP? What are your reasons?", "What are your specific conditions for supporting the development of NNP?", and "During the development of NNP, what types of assistance do you need? (e.g., ecological compensation, technical support, etc.)?". The interviews lasted from $45 \mathrm{~min}$ to an hour in each township, and the participants were free to express their opinions.

\section{Dependent Variables}

To gauge the general attitudes toward the project, respondents were presented with a closed-ended question-"Do you support the development of NNP?" — with three answer options to choose from ("support", "do not support", and "support under certain conditions"). Following that, the in-depth interviews focused mostly on those who responded with "support under certain conditions" and "do not support".

\section{Independent Variables}

Gender, age, educational level, and ethnicity were selected as control variables. Perceptions toward ecological, economic, political, and cultural impacts were selected as independent variables to measure the resident attitudes toward the development of NNP. The specific questions are shown in Table 1.

\subsubsection{Data Collection and Field Survey}

The project team was divided into five research groups. Thanks to the joint support and coordination of the Guangdong Forestry Bureau, Qingyuan Municipal Government, Shaoguan Municipal Government, as well as the involved subordinate governments, village committees, and nature reserve management agencies at all levels, the field research was carried out in an orderly fashion in 7 counties (cities, districts) and 23 villages and towns under the jurisdiction of Shaoguan and Qingyuan between August and September 2020. To make the project more understandable to the public, the project team published notifications in the major local media (Shaoguan Daily, Qingyuan Daily), as well as related townships, village committees, firms and institutions, and agencies for the administration of nature reserve before the research began. The first round of work, which included the distribution of questionnaires, took place from 18 to 28 August 2020, followed by a series of community workshops organized by village committees in 23 townships across the project region from 18 August to 5 September 2020, as well as a supplementary survey performed from 5 to 15 September 2020. All of the survey data were coded and reviewed to ensure completeness and accuracy. Finally, 3975 questionnaires were returned, with 3586 being valid for a response rate of $90.2 \%$. A total of 173 interviews were completed in 23 townships and the interview records comprised 20,000 words. In this research, it was not intended to analyze the interview materials in quantitative terms; they were used to support or further explain the quantitative survey results. The content materials were analyzed with SPSS 23.0 and NVivo 11 separately.

\section{Results}

\subsection{Results of Descriptive Statistical Analysis}

According to the demographic characteristics of the sample (Table 2), males made up the majority of the respondents $(91.1 \%)$ whereas female involvement was relatively low $(8.9 \%)$ due to the fact that the survey was done on a household basis. In general, men play a vital role in families, with a stronger voice and decision-making power, particularly in rural China, while women engaged in public issues, such as natural resources, have typically been constrained by traditional rural social norms [37]. Approximately $80 \%$ of respondents were Han Chinese, with the remainder being ethnic minorities, mostly Yao. 
They lived in or near the core protected zones, and therefore will become the most impacted groups that have to relocate to make way for the park and natural ecology. Roughly $80 \%$ of those who responded had junior high or less schooling, and the majority of the residents were elderly people $(69.7 \%$ of respondents were more than 40 years old). Because the residents were older and with lower educational levels, the construction of NNP will have an impact on their traditional lifestyles of relying on natural resources, which will affect their attitudes toward the construction of NNP. Table 1 shows that even at the early stages of the development of NPs, residents have different perceptions of social impacts. Compared with political and cultural influences, the residents are more sensitive to the ecological and economic impacts caused by the development of NNP. Although the residents have dissimilar perceptions of the social impacts, the majority still expressed support $(29.8 \%)$ or conditional support (57.9\%) for NNP.

Table 2. Demographic profile of respondents.

\begin{tabular}{|c|c|c|c|c|c|}
\hline \multicolumn{2}{|c|}{ Characteristics } & \multirow{2}{*}{$\begin{array}{c}\% \\
91.1\end{array}$} & \multicolumn{2}{|c|}{ Characteristics } & \multirow{2}{*}{$\begin{array}{c}\mathbf{\%} \\
29.8\end{array}$} \\
\hline Gender & Male & & $\begin{array}{l}\text { Family income } \\
\text { (CNY per year) }\end{array}$ & $\leq 10,000$ & \\
\hline \multirow{3}{*}{ Ethnicity } & Female & 8.9 & Income & $10,001-30,000$ & 31.3 \\
\hline & Han & 78.8 & & $30,000-60,000$ & 20.4 \\
\hline & Minority & 21.2 & & $60,000-100,000$ & 11.2 \\
\hline \multirow[t]{6}{*}{ Age } & $\leq 20$ & 0.3 & & $\geq 100,000$ & 7.3 \\
\hline & $21-30$ & 3.5 & Education & Primary school & 32.9 \\
\hline & $31-40$ & 26.5 & & Junior high school & 54.2 \\
\hline & $41-50$ & 13.8 & & Senior high school & 10.1 \\
\hline & $51-60$ & 29.4 & & $\begin{array}{l}\text { University or junior } \\
\text { college }\end{array}$ & 2.8 \\
\hline & $\geq 60$ & 26.5 & & & \\
\hline
\end{tabular}

Perceptions indicate the subjective attitudes or acceptance of respondents with respect to the project [38].To better understand the situation of farm households, a series of crosstabulations were constructed to examine the associations between the seven variables of local resident perceptions of the SIA and their attitudes toward the development of NNP (Figure 2). The crosstabulations shows that perceptions of the social impacts from different dimensions were independently related to supportive attitudes regarding the development of NNP. Residents with dissimilar attitudes toward the park development had significantly different perceptions of the social impacts. For example, residents who supported the development of NNP thought the project would promote local tourism, the economy, and employment. A multinomial logistic regression analysis was applied to analyze the observed differences with the descriptive results presented in the next section.

\subsection{Results of Multinomial Logistic Regression Results}

Respondents who "did not support the development of NNP" were used as a reference group. Then, the influence of the demographic characteristics and the social impact perceptions on attitudes toward the park development were further analyzed through a multinomial logistic regression (Table 3).

In the control variable group, the residents' attitude toward NNP was related to education levels and ethnic groups. In model A, compared to these with senior high school education, those with only primary school education were less likely to support the development $\left(\beta_{1}=-0.235, p<0.1\right)$, so as in model B $\left(\beta_{2}=0.446, p<0.1\right)$. In model A, compared with ethnic minorities, Han people were more inclined to support the development $\left(\beta_{1}=0.485, p<0.1\right)$. In model $\mathrm{B}$, ethnic minorities preferred to support the development of NNP under certain conditions $\left(\beta_{2}=-1.034, p<0.01\right)$. 


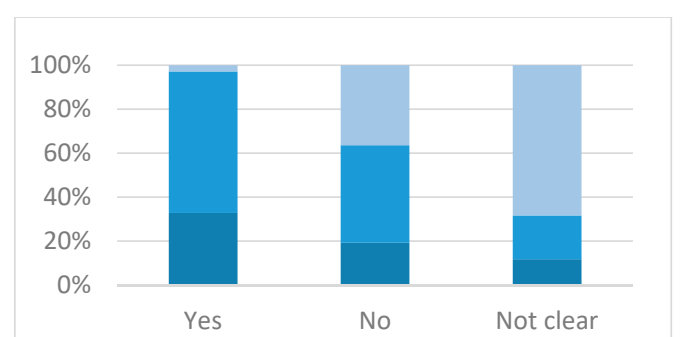

(a) Natural ecological environment(CL 1)

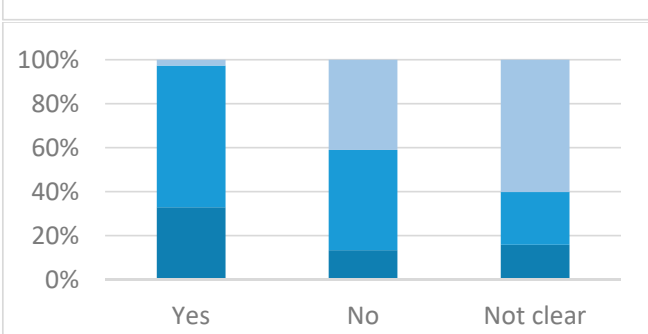

(c) Tourism development (EC 2)

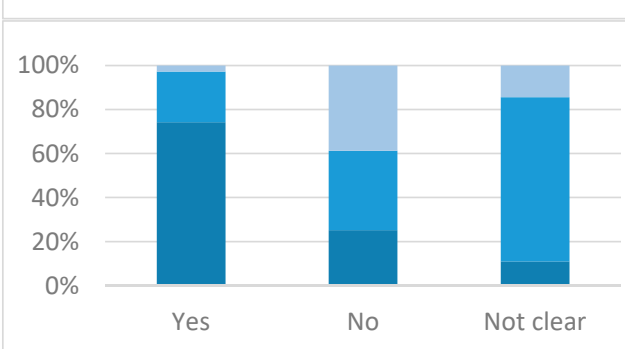

(e) Benefit the poor (PL 1)

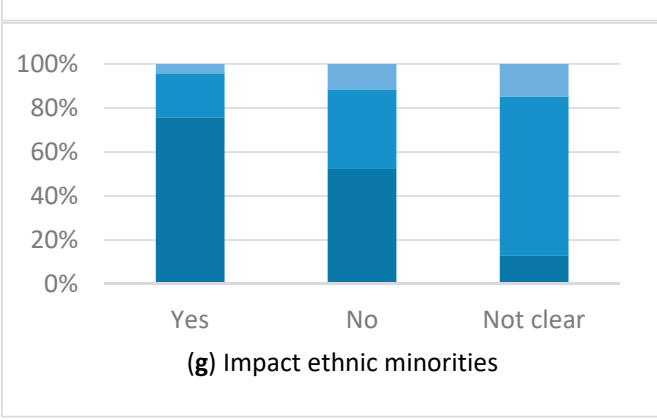

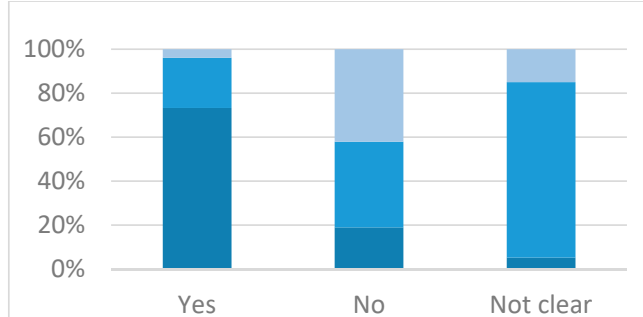

(b) Economic development (EC 1)

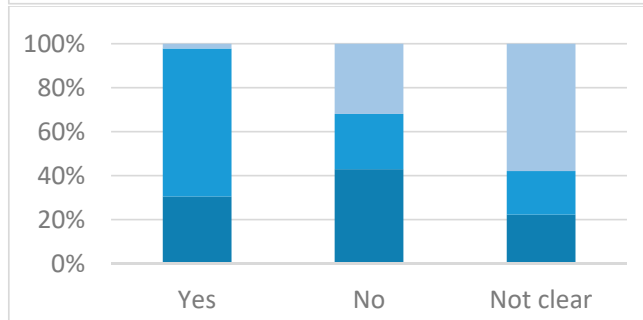

(d) Employment opportunities (EC 3)

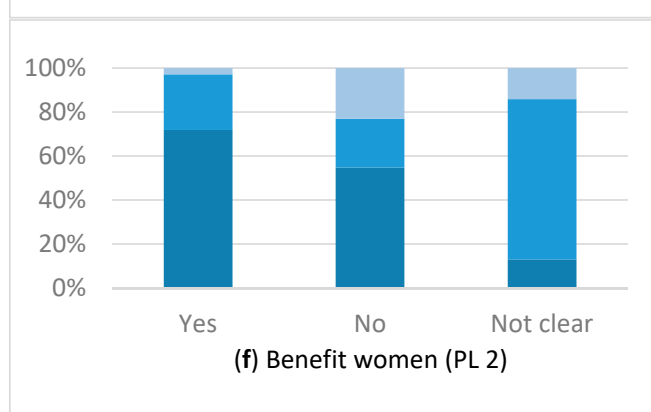

$$
\begin{aligned}
& \text { Not support } \\
& \text { Support under certain conditions } \\
& \text { Support }
\end{aligned}
$$

Figure 2. Descriptive analyses of the association between resident attitudes toward NNP and perceptions of the SIA. (a) Natural ecological environment(CL 1), (b) Economic development (EC 1), (c) Tourism development (EC 2), (d) Employment opportunities (EC 3), (e) Benefit the poor (PL 1), (f) Benefit women (PL 2), (g) Impact ethnic minorities.

In the independent variables group, resident perceptions of the four aspects of the SIA were related to the attitudes toward the development of NNP. For ecological impact, residents who supported the development of NNP agreed with the improvement of ecological environmental impact $\left(\beta_{1}=1.908, p<0.05\right)$ in model $\mathrm{A}$. In the model $\mathrm{B}$, the residents were more likely to support the development of NNP under certain conditions when they were surer about the positive or negative ecological impact brought by the NNP $\left(\beta_{2}=2.391\right.$, $\left.p<0.001 ; \beta_{2}=1.910, p<0.01\right)$. Thus, people were more likely not to support the development of NNP if they were not clear about its ecological impacts. For economic impact, the residents were inclined to support NNP if they agreed that it would promote the local economy $\left(\beta_{1}=1.469, p<0.01\right)$, local tourism $\left(\beta_{1}=0.632, p<0.05\right)$, and increase employment opportunities for the local community $\left(\beta_{1}=0.774, p<0.05\right)$. For political impact, people who thought the construction of NNP would not benefit the poor tended not to support the project $\left(\beta_{1}=-0.846, p<0.05\right)$. The residents' perceptions of women's benefit were 
not significantly related to attitudes toward the park development. For cultural impacts, compared to those who were not clear if NPP would have an impact on the customs and religions of local ethnic minorities, the residents were more likely to support the project if they were clear about what changes would be brought by NNP $\left(\beta_{1}=1.143, p<0.01\right)$.

Table 3. Results of multinomial logistic regression.

\begin{tabular}{|c|c|c|c|c|}
\hline \multirow{3}{*}{ Variables } & \multicolumn{2}{|c|}{ Model A } & \multicolumn{2}{|c|}{ Model B } \\
\hline & \multicolumn{2}{|c|}{ Supportive } & \multicolumn{2}{|c|}{$\begin{array}{c}\text { Supportive } \\
\text { (Under Certain Conditions) }\end{array}$} \\
\hline & $\beta_{1}$ & SE & $\beta_{2}$ & SE \\
\hline \multicolumn{5}{|l|}{ Characteristics } \\
\hline \multicolumn{5}{|l|}{ Gender (Ref: Male) } \\
\hline Female & -0.161 & 0.261 & 0.202 & 0.252 \\
\hline \multicolumn{5}{|c|}{ Education (Ref: Senior high school) } \\
\hline Primary school & $-0.235 *$ & 0.269 & $-0.446^{*}$ & 0.250 \\
\hline Junior high school & $-0.508^{* *}$ & 0.245 & $-0.718^{* *}$ & 0.236 \\
\hline \multicolumn{5}{|l|}{ Ethnicity (Ref: Minority) } \\
\hline Han & $0.485^{*}$ & 0.284 & $-1.034^{* * *}$ & 0.255 \\
\hline Age & 0.003 & 0.008 & 0.010 & 0.007 \\
\hline \multicolumn{5}{|l|}{$\begin{array}{l}\text { Ecological Impact Perception } \\
\text { EL } 1 \text { (Ref: Not Clear) }\end{array}$} \\
\hline Yes & $1.980 * *$ & 0.257 & $2.391^{* * *}$ & 0.236 \\
\hline No & 0.669 & 0.462 & $1.910^{* * *}$ & 0.382 \\
\hline \multicolumn{5}{|l|}{ Economics Impact Perception } \\
\hline Yes & $1.469^{* * *}$ & 0.255 & $-1.619^{* * *}$ & 0.255 \\
\hline No & 0.165 & 0.362 & $-1.208^{* * *}$ & 0.339 \\
\hline \multicolumn{5}{|l|}{ EC 2 (Ref: Not Clear) } \\
\hline Yes & $0.632 * *$ & 0.267 & $1.194^{* * *}$ & 0.257 \\
\hline No & $-\underset{* * *}{-1.386}$ & 0.421 & $1.009^{* *}$ & 0.350 \\
\hline \multicolumn{5}{|l|}{ EC 3 (Ref: Not Clear) } \\
\hline Yes & $0.774^{* *}$ & 0.234 & $2.400^{* * *}$ & 0.220 \\
\hline No & 0.376 & 0.342 & 0.445 & 0.336 \\
\hline \multicolumn{5}{|l|}{ Political Impact Perception } \\
\hline Yes & 0.316 & 0.308 & $-0.669^{* *}$ & 0.319 \\
\hline No & $-0.846^{* *}$ & 0.345 & -0.696 & 0.349 \\
\hline \multicolumn{5}{|l|}{ PL 2 (Ref: Not Clear) } \\
\hline Yes & 0.271 & 0.324 & 0.452 & 0.336 \\
\hline No & -0.271 & 0.309 & $-0.951^{* *}$ & 0.312 \\
\hline \multicolumn{5}{|l|}{$\begin{array}{l}\text { Cultural Impaction Perception } \\
\text { CL } 1 \text { (Ref: Not Clear) }\end{array}$} \\
\hline Yes & $1.143^{* * *}$ & 0.309 & 0.317 & 0.295 \\
\hline No & 0.451 & 0.260 & 0.493 * & 0.261 \\
\hline Model -2 log-likelihood & & & 3294.352 & \\
\hline$x^{2}$ & & & 4261.167 & \\
\hline
\end{tabular}

\section{Findings and Discussion}

\subsection{Influence of Individual Differences on Supporting Attitude of National Park}

Despite the fact that age and education have been identified as fundamental factors in previous research on the environment and PA perceptions, few substantial impacts were observed [39]. A recent study on the Wuyi Mountains National Park determined that people with higher levels of education were more likely to appreciate the importance of ecosystem services than the less educated, thus further impacting the support for NP policy and the effectiveness with which it is implemented [14]. The aforementioned research conclusion is similar to the Wuyi study findings. During the interviews, villagers with higher educational 
attainment expressed more concern about the impact of environmental deterioration and strongly believed that building NNP would improve their living environments and quality of life [40]. Younger individuals are typically better educated and more open to new concepts, while seniors tend to have greater trouble adapting to life and livelihood changes. As a result, they are opposed to the development of NNP. As a result, the government must pay particular attention to the impact of NNP development on older residents and enhance the compensation and social security benefits systems to garner more support. Beyond that, education is thought to impart not only knowledge but survival skills [25] that allow people to be better equipped with the capacity to resist risks in the face of negative social impacts caused by the construction of NNP and thus to increase project support.

Most of the residents in the strictly protected zone (according to the "Master Plan of NNP", the NNP area is divided into strictly protected zones and general control zones. Strictly protected areas refer to zones with high ecological value and no human activities) are ethnic minorities who have lived on this land for longer periods than the Han Chinese. Due to the construction of NNP, they will be forced to leave their homes, on which they rely, through the procedure of ecological relocation. Although the administrative department suggested land replacement and ecological compensation to reduce the losses of these residents, the exact compensation system and standards were not determined in the initial development stage, and this resulted in concerns among those impacted about the future. Accordingly, some ethnic villagers raised a barrage of questions about their lands, subsistence practices, and livelihoods_- "What will happen to our lands after we move out? We'd rather live a stable life in the mountains. What can we do now that we've relocated?" (male, 48 years). In addition, the limited access to modern life makes it difficult for ethnic minority residents to adapt and assimilate into the relocation sites. Because of their inability to adjust, some of them eventually opt to return. Under these circumstances, NNP is seen as taking possession of their lands and forcing them to abandon their homes, and thus many are opposed to the project's execution.

\subsection{Reasons for Differences in Perception of Social Impact and Support Concerns of Local Residents}

Previous research has demonstrated that the long-term presence and administration of protected areas is a particular condition that leads to social perceptions in communities. The results of the interviews with the local residents revealed that their perceptions toward the social impacts were primarily derived from the understanding of NPs. Thus, they believed that the value of a NP comes from its ecosystems, with parks providing sustainable livelihoods for individuals and families, as well as employment opportunities and a boost to community economies. Moreover, the associated initiatives in the early stages of NNP development are mostly linked to ecological and economic interests. For example, the categorization of areas may exert a direct impact on access to natural resources to support livelihoods. Therefore, local residents are more sensitive to the ecological and economic impacts and are more concerned with personal gains than with political and cultural impacts.

Since the establishment of Nanling National Nature Reserve in 1994, the local populations have been exposed to a variety of natural resource planning initiatives and management, helping them progressively cultivate and maintain an awareness of environmental and ecological conservation. In the meantime, what has been accomplished in protection management has also served as a basis for the development of socio-economic perceptions. During the interviews, the vast majority of local people voiced their approval of environmental protection- "We feel that NP building is of great help in preserving our mountains and rivers", said a 45-year-old man; "The establishment of the NP is a good thing that benefits the country and the people, and I wholeheartedly support it", said a 53-year-old man. The way people think about and perceive natural resources is influenced by how the resources will be utilized. Some local residents stated that they would not cut down forests with economic value but hoped that ancestral forest lands would be retained and left as an asset for their descendants rather than categorized as strictly protected zones. These 
lands and forests are not just a place for production and living, but a source of emotional sustenance. Because of the emotional attachment to lands, local residents were willing to forego some economic interests to support ecological sustainability and NNP.

The local residents were more sensitive to economic impacts, as they expected the NP to improve a wide range of community well-being dimensions from economic conditions to the environment and quality of life. Previous studies have also found that, among the four perceived impacts of NPs, the values associated with culture and ecology are outweighed by the economic benefits. "We just want to know if we may start a homestay business or run a farmhouse after NNP is completed. Are preferential policies going to exist? Of course, if at all feasible, we would support it", said a 28-year-old female resident. For those opposed, the development of NNP will impose restrictions on the exploitation of natural resources, raising economic concerns. In Boluo Town, for example, part of the forest lands are maintained by NNP. Some areas are rented by the China Forest Ecological Industry Demonstration Base for the development of nature-based tourism, and others are utilized by the local residents for bamboo shoot plantations. The local people had expected that NNP would enhance their living conditions; instead, the development hampered their regular production and livelihoods, sometimes reverting them to poverty and escalating social conflicts. As a consequence, several were vehemently opposed to the development. "What're the benefits of the NNP? It'll just make things worse for us", (male, 42 years) said a respondent during the interview. In addition, NNP is situated in an area abundant in water resources, with many small- and medium-sized hydroelectric facilities. Some of the locals were project participants and could earn a dividend annually at the commencement of the building of hydropower stations. With the construction of NNP, however, hydropower projects, which do not comply with the "Master Plan", have gradually been shut down and removed, resulting in heavy job losses in the area. According to prior research, the cost of nature conservation is often borne by local communities, as they restrain residents from engaging in traditional production activities based on natural resources, particularly among the poorest groups [41]. Additionally, only if economic gains are greater than before construction will people support NP projects [42,43]. The results further demonstrated that the economic benefits should be prioritized during the initial stages of NP construction, namely, how to promote the transformation of green industries to minimize the negative social effects caused-for instance, technical support and financial compensation are the most direct and viable means to assist local people in recognizing and embracing NPs.

Poverty is a practical concern faced by the vast majority of residents in the PAs of developing countries [44], and their subsistence activities often jeopardize the natural resources and environmental management of the reserves. Some scholars have recommended that anthropogenic disturbances be addressed by alleviating poverty [45]. Residents in and around NNP are hopeful that the construction will help ease their poor conditions. "My life is so hard. Will our earnings rise after the park is built? And is there an increased amount of ecological compensation?" a respondent asked (male, 53 years). Similar to the initial goal of "rural revival" initiated by France, China's NPs aim to alleviate poverty while preserving ecological systems for the local communities. In the researchers' view, when it comes to the development of NPs, special attention should be paid to local poverty, and alternative jobs and compensation criteria should be factored into the planning process from the beginning. As indicated by the analysis of gender disparities, whether women will benefit from the NP is not necessarily a source of concern among residents. Previous studies have indicated that women and men have different needs, priorities, and resource use patterns when interacting with the environment $[30,46]$. Women are more passive than their male counterparts, but they are frequently excluded from power and decision-making processes. This unequal relationship is regarded as one of the most common causes of ineffective management practices and less community engagement in NPs [7]. It was also found in this survey that the proportion of women in local governance agencies was low.

Similar to the Native Americans of Antelope Canyon, who have viewed the Red Rock Canyon as a sacred place to commune with their gods, the local residents of NNP have 
long considered forest lands to be holy sites where they may bury their ancestors. This cultural legacy is also apparent in this study. In the cultural impact perception group, those who felt the customs and practices of ethnic minorities would be affected indicated higher support for the construction of NNP. The Yao, whose ancestors have been residing in the mountains since ancient times, are the majority within NNP. The Yao village is classified as a core protected zone, and thus the entire community is required to relocate to the general control area. During the interviews, residents indicated support for the NP, provided the traditional minority culture, such as houses and buildings, was preserved. "Even if we move out, we want to come back and look at the houses", one respondent stated (female, 36 years). Culture, as part of the lives of local people, is interwoven in their interactions with nature (local culture) and can also contribute to livelihoods (e.g., via ecotourism). Therefore, when analyzing the social impacts of NP on communities, extra emphasis should be allocated to the perceptions of ecological and cultural impacts on activities that mold people's minds and behaviors. Only in this manner can policymakers develop a better understanding of the context in which local groups support the NP under specific circumstances.

\section{Conclusions and Policy Implications}

This research explored the attitudes toward NP development from an endogenous viewpoint by examining the perceived social impacts of the proposed NNP project among the local residents. The results revealed that the social impacts perceived by local people toward NNP influenced their attitudes at an early stage of the project. The lack of knowledge caused residents to be anxious and conflicted about the NP; thus, they gave support to the NP under certain conditions. These concerns arose largely from uncertainties as to how they will live in the future. However, it filled some people with dread for their future livelihoods as a result of poor conservation measures and incentives in the past. Although there were anticipated positive and negative societal consequences, the local people noticed more favorable impacts throughout the planning stages of the NP. On the other hand, the new management system has yet to be fully transparent and how it will be different from previous PAs. It will be difficult to harmonize the "bottom-up" approach with resident involvement with the "top-down" political system. There has unavoidably been a combination of endogenous (bottom-up) and exogenous (top-down) forces throughout the social and economic development process. Despite the challenges, the key is to strike a balance between internal and external control and to ensure more access and community empowerment so that the local people may reap greater benefits from the process.

Three strategies of gaining local support during the early stages of building the national park were determined and create possible conditions for community involvement. First, efforts must be made to strengthen awareness of NNP among the residents and local communities through lectures, slogans, and other ways, to improve their understanding of the national policies. Additionally, policymakers may also better comprehend and balance protection targets and resident interests, as well as identify conflict points and solutions to fulfil the needs and appeals for local peoples. Second, since there are differing perceptions toward the social impacts of the NP, different livelihood restoration and benefit sharing programs should be tailored to meet a variety of demands [47]. The social impacts of NP building perceived by vulnerable groups, such as ethnic minorities and women, should be given special consideration. Material security, e.g., ecological compensation, is the most pragmatic and immediate approach to helping residents, whereas education and training are more long term and sustainable. How to integrate local resources to effectively translate the green economy into greater employment is the key planning issue with which policymakers must engage. Third, the development of the NP has dynamic and profound implications that may bring about changes in attitudes, policies and strategies, and even result in residents having a greater say in local development [48]. The quest for a NP where human and nature coexist in harmony can only be accomplished by empowering local communities while ensuring that their values, ways of thinking, and 
significance are aligned with national participatory conservation initiatives. In addition, resilient governance provides a viable framework for the relationship between the NP administration department and communities [49]. By guiding the community to participate in the governance of the NP and providing the corresponding guaranteed mechanisms, the communities gradually change from passive participation to active participation, which helps to establish top-down and bottom-up paths.

The development of NPs in China is a policy initiative that involves a nationwide effort to undertake institutional reform. The Chinese government provides residents with various exogenous support factors, such as economic subsidies, technical aid, and other forms of welfare. This research explored ways to encourage active community participation in the local development from an endogenous perspective. This research has some limitations. For example, there was an unequal gender representation in responses; however, the local cultural traditions were followed and this is a recognized limitation of the results. Additionally, it is not sufficient to evaluate the social impacts only from a community perspective in a centralized country like China. The social impacts of NP development are diverse, and the attitudes of different stakeholders, such as local government and enterprises, toward NP development are equally important. This is affected by how effectively the relevant systems and policies are promoted and implemented. Therefore, our study established a baseline for the social impacts of the NP project and, on that basis, to adjust policy guidelines and develop a community feedback mechanism to meet the different demands, minimize negative social impacts as much as possible, and gain more support from residents and communities. The results of this research provide not only a baseline for the social impacts of NNP construction [50], but also a reference of value for assessing the effectiveness of policy implementation in the future.

Author Contributions: Conceptualization, Q.D. and X.C.; methodology, Q.D. and B.Z.; software, Q.D. and B.Z.; validation, X.C.; formal analysis, Q.D. and A.M.M.; investigation, Q.D.; data curation, B.Z.; writing-original draft preparation, Q.D.; writing—review and editing, A.M.M. and X.C.; visualization, Q.D.; funding acquisition, Q.D. and B.Z. All authors have read and agreed to the published version of the manuscript.

Funding: This research was funded by Hubei Province Philosophy Social Sciences Research Project, China (grant number 20Q121), National Natural Science Foundation of China (grant number 41901170), Guangdong Basic and Applied Basic Research Foundation (grant number 2019A1515011385), and Innovation Group Project of Southern Marine Science and Engineering Guangdong Laboratory (Zhuhai) (grant number 311021018).

Institutional Review Board Statement: We choose to exclude this statement, because the study did not require ethical approval.

Informed Consent Statement: Informed consent was obtained from all subjects involved in the study.

Data Availability Statement: Not applicable.

Conflicts of Interest: The authors declare no conflict of interest.

\section{References}

1. Dudley, N. Guidelines for Applying Protected Area Management Categories; IUCN: Gland, Switzerland, 2008; pp. 16-17.

2. Shen, X.; Li, S.; McShea, W.J.; Wang, D.; Yu, J.; Shi, X.; Dong, W.; Mi, X.; Ma, K. Effectiveness of management zoning designed for flagship species in protecting sympatric species. Conserv. Biol. 2020, 34, 158-167. [CrossRef] [PubMed]

3. Tvedt, M.W.; Young, T. Beyond Access: Exploring Implementation of the Fair and Equitable Sharing Commitment in the CBD; IUCN: Gland, Switzerland, 2007; pp. 5-19.

4. Karki, S.T. Do protected areas and conservation incentives contribute to sustainable livelihoods? A case study of Bardia National Park, Nepal. J. Environ. Manag. 2013, 128, 988-999. [CrossRef] [PubMed]

5. Mehnen, N.; Mose, I.; Strijker, D. Governance and sense of place: Half a century of a German nature park. Environ. Policy Gov. 2013, 23, 46-62. [CrossRef]

6. Vanclay, F. Principles to gain a social licence to operate for green initiatives and biodiversity projects. Curr. Opin. Environ. Sustain. 2017, 29, 48-56. [CrossRef] 
7. Nchanji, Y.K.; Ramcilovic-Suominen, S.; Kotilainen, J. Power imbalances, social inequalities and gender roles as barriers to true participation in national park management: The case of Korup National Park, Cameroon. For. Policy Econ. 2021, $130,102527$. [CrossRef]

8. Vanclay, F.; Esteves, A.M. New Directions in Social Impact Assessment: Conceptual and Methodological Advances; Edward Elgar Publishing: Northampton, UK, 2011; pp. 4-5.

9. Franks, P.; Small, R. Social assessment for protected areas (SAPA). In Methodology Manual for SAPA Facilitators; IIED: London, UK, 2016.

10. Vanclay, F. International principles for social impact assessment. Impact Assess. Proj. Apprais. 2003, 21, 5-12. [CrossRef]

11. Vanclay, F. Principles for social impact assessment: A critical comparison between the international and US documents. Environ. Impact Assess. Rev. 2006, 26, 3-14. [CrossRef]

12. West, P.; Igoe, J.; Brockington, D. Parks and Peoples: The Social Impact of Protected Areas. Annu. Rev. Anthropol. 2006, 35, 251-277. [CrossRef]

13. Pullin, A.S.; Bangpan, M.; Dalrymple, S.; Dickson, K.; Haddaway, N.R.; Healey, J.R.; Hauari, H.; Hockley, N.; Jones, J.P.; Knight, T. Human well-being impacts of terrestrial protected areas. Environ. Evid. 2013, 2, 1-41. [CrossRef]

14. He, S.; Su, Y.; Wang, L.; Gallagher, L.; Cheng, H. Taking an ecosystem services approach for a new national park system in China. Resour. Conserv. Recycl. 2018, 137, 136-144. [CrossRef]

15. Kuenzi, C.; McNeely, J. Nature-based tourism. In Global Risk Governance; Springer: Berlin/Heidelberg, Germany, 2008; pp. $155-178$.

16. Waitt, G.; Lane, R.; Head, L. The boundaries of nature tourism. Ann. Tour. Res. 2003, 30, 523-545. [CrossRef]

17. Priskin, J. Assessment of natural resources for nature-based tourism: The case of the Central Coast Region of Western Australia. Tour. Manag. 2001, 22, 637-648. [CrossRef]

18. West, P.; Carrier, J. Ecotourism and authenticity: Getting away from it all? Curr. Anthropol. 2004, 45, 483-498. [CrossRef]

19. Cernea, M.M.; Schmidt-Soltau, K. Poverty risks and national parks: Policy issues in conservation and resettlement. World Dev. 2006, 34, 1808-1830. [CrossRef]

20. Ferraro, P.J.; Hanauer, M.M. Through what mechanisms do protected areas affect environmental and social outcomes? Philos. Trans. R. Soc. B Biol. Sci. 2015, 370, 20140267. [CrossRef] [PubMed]

21. Eneji, V.; Gubo, Q.; Okpiliya, F.; Aniah, E.; Eni, D.; Afangide, D. Problems of public participation in biodiversity conservation: The Nigerian scenario. Impact Assess. Proj. Apprais. 2009, 27, 301-307. [CrossRef]

22. Ferraro, P.J.; Hanauer, M.M. Quantifying causal mechanisms to determine how protected areas affect poverty through changes in ecosystem services and infrastructure. Proc. Natl. Acad. Sci. USA 2014, 111, 4332-4337. [CrossRef] [PubMed]

23. Canavire-Bacarreza, G.; Hanauer, M.M. Estimating the impacts of Bolivia's protected areas on poverty. World Dev. 2013, 41, 265-285. [CrossRef]

24. Clements, T.; Suon, S.; Wilkie, D.S.; Milner-Gulland, E.J. Impacts of Protected Areas on Local Livelihoods in Cambodia. World Dev. 2014, 64, S125-S134. [CrossRef]

25. Zhang, J.; Yin, N.; Li, Y.; Yu, J.; Zhao, W.; Liu, Y.; Fu, B.; Wang, S. Socioeconomic impacts of a protected area in China: An assessment from rural communities of Qianjiangyuan National Park Pilot. Land Use Policy 2020, 99, 104849. [CrossRef]

26. Ward, C.; Stringer, L.C.; Holmes, G. Protected area co-management and perceived livelihood impacts. J. Environ. Manag. 2018, 228, 1-12. [CrossRef] [PubMed]

27. Rasker, R. Rural development, conservation, and public policy in the greater Yellowstone ecosystem. Soc. Nat. Resour. 1993, 6, 109-126. [CrossRef]

28. Holt, F.L. The Catch-22 of Conservation: Indigenous Peoples, Biologists, and Cultural Change. Hum. Ecol. 2005, 33, 199-215. [CrossRef]

29. Roth, R. On the colonial margins and in the global hotspot: Park-people conflicts in highland Thailand. Asia Pac. Viewp. 2004, 45, 13-32. [CrossRef]

30. Vanclay, F. The potential application of social impact assessment in integrated coastal zone management. Ocean Coast. Manag. 2012, 68, 149-156. [CrossRef]

31. Vanclay, F. Conceptualising social impacts. Environ. Impact Assess. Rev. 2002, 22, 183-211. [CrossRef]

32. Schrekenberg, K. Social Assessment of Conservation Initiatives: A Review of Rapid Methodologies; IIED: London, UK, 2010.

33. McNeely, J.A. Protected areas for the 21st century: Working to provide benefits to society. Biodivers. Conserv. 1994, 3, 390-405. [CrossRef]

34. Esteves, A.M.; Franks, D.; Vanclay, F. Social impact assessment: The state of the art. Impact Assess. Proj. Apprais. $2012,30,34-42$. [CrossRef]

35. Wang, J.-H.Z. National parks in China: Parks for people or for the nation? Land Use Policy 2019, 81, 825-833. [CrossRef]

36. Zhang, Y.; Xiao, X.; Cao, R.; Zheng, C.; Guo, Y.; Gong, W.; Wei, Z. How important is community participation to eco-environmental conservation in protected areas? From the perspective of predicting locals' pro-environmental behaviours. Sci. Total Environ. 2020, 739, 139889. [CrossRef]

37. Evans, K.; Flores, S.; Larson, A.M.; Marchena, R.; Müller, P.; Pikitle, A. Women's Studies International Forum; Elsevier: Amsterdam, The Netherlands, 2017; pp. 37-46. 
38. Zhang, J.; Luo, M.; Cao, S. How deep is China's environmental Kuznets curve? An analysis based on ecological restoration under the Grain for Green program. Land Use Policy 2018, 70, 647-653. [CrossRef]

39. Ghoddousi, S.; Pintassilgo, P.; Mendes, J.; Ghoddousi, A.; Sequeira, B. Tourism and nature conservation: A case study in Golestan National Park, Iran. Tour. Manag. Perspect. 2018, 26, 20-27. [CrossRef]

40. Satyanarayana, B.; Bhanderi, P.; Debry, M.; Maniatis, D.; Foré, F.; Badgie, D.; Jammeh, K.; Vanwing, T.; Farcy, C.; Koedam, N.; et al. A Socio-Ecological Assessment Aiming at Improved Forest Resource Management and Sustainable Ecotourism Development in the Mangroves of Tanbi Wetland National Park, The Gambia, West Africa. AMBIO 2012, 41, 513-526. [CrossRef] [PubMed]

41. Cho, S.-H.; Thiel, K.; Armsworth, P.R.; Sharma, B.P. Effects of protected area size on conservation return on investment. Environ. Manag. 2019, 63, 777-788. [CrossRef] [PubMed]

42. Schelhas, J.; Sherman, R.E.; Fahey, T.J.; Lassoie, J.P. Natural Resources Forum; Blackwell Publishing Ltd.: Oxford, UK; Boston, MA, USA, 2002; pp. 140-149.

43. Sachs, J.D.; Reid, W.V. Investments toward sustainable development. Sci. Wash. 2006, 312, 1002. [CrossRef]

44. Snyman, S.L. The role of tourism employment in poverty reduction and community perceptions of conservation and tourism in southern Africa. J. Sustain. Tour. 2012, 20, 395-416. [CrossRef]

45. Agrawal, A. Matching and mechanisms in protected area and poverty alleviation research. Proc. Natl. Acad. Sci. USA 2014, 111, 3909-3910. [CrossRef]

46. Marin, A.B.; Kuriakose, A.T. Gender and Sustainable Forest Management: Entry Points for Design and Implementation; Climate Investment Funds: 2017. Available online: https://www.climateinvestmentfunds.org/sites/cif_enc/files/knowledgedocuments/gender_and_sustainable_forest_management.pdf (accessed on 23 September 2021).

47. Kemp, D.; Vanclay, F. Human rights and impact assessment: Clarifying the connections in practice. Impact Assess. Proj. Apprais. 2013, 31, 86-96. [CrossRef]

48. Hidle, K. How national parks change a rural municipality's development strategies-The Skjåk case, Norway. J. Rural Stud. 2019, 72, 174-185. [CrossRef]

49. Chen, S.; Sun, X.; Su, S. A Study of the Mechanism of Community Participation in Resilient Governance of National Parks: With Wuyishan National Park as a Case. Sustainability 2021, 13, 10090. [CrossRef]

50. Jones, N.; McGinlay, J.; Dimitrakopoulos, P.G. Improving social impact assessment of protected areas: A review of the literature and directions for future research. Environ. Impact Assess. Rev. 2017, 64, 1-7. [CrossRef] 